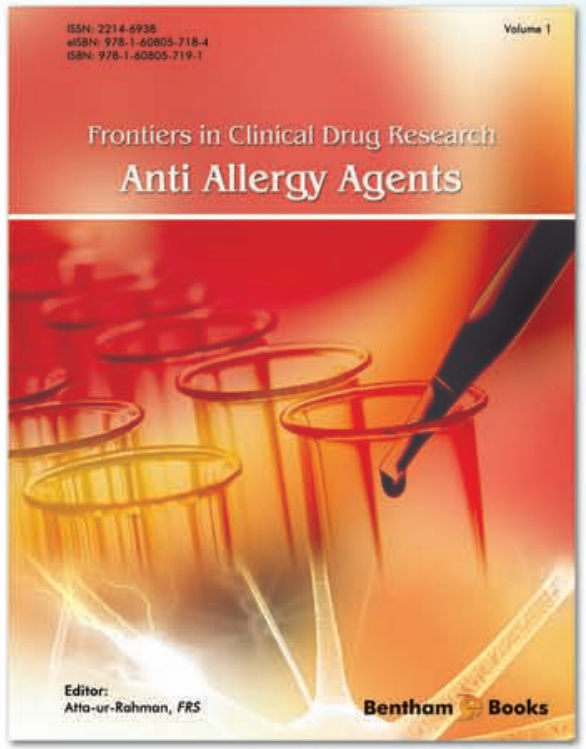

\title{
Editor:
}

\section{Atta-ur-Rahman, FRS}

UK

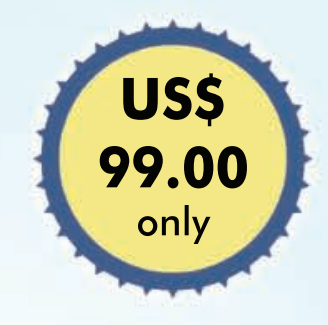

elSBN: 978-1-60805-718-4

\section{Frontiers in Clinical Drug Research - Anti-Allergy Agents}

\section{WW'.henthamseience.com/Ghooks/9781608057184}

\section{About the ebook}

Frontiers in Clinical Drug Research - Anti-Allergy Agents is an exciting eBook series comprising a selection of updated review articles relevant to the recent development of pharmacological agents used for the treatment of allergies. The scope of the reviews includes clinical trials of anti-inflammatory and anti-allergic drugs, drug delivery strategies used to treat specific allergies (such as inflammation, asthma and dermatological allergies), lifestyle dependent modes of therapies and the immunological or metabolic mechanisms that are of interest to researchers as targets for new drugs.

\section{Contents}

- Topical Use of Calcineurin Inhibitors in Dermatology

- New Therapies for Asthma: What Else Besides Steroids?

- Anti-Allergy Agents in Patients Practicing Sports

(-) Omalizumab Therapy for Allergic Diseases

- Therapeutics for Allergy Management

- Main Food Allergic Therapies (Promising Ongoing Projects)

For Advertising Inquiries: Contact: marketing@benthamscience.org 